\section{Absorção de Mão-de-Obra, Escolaridade e Salários na Hotelaria Brasileira}

\section{Manuel Enriquez, Garcia}

RESUMO: Este artigo, com base nos resultados da pesquisa Condições e Perspectivas do Mercado de Tra balho no Setor Turismo - Segmento Hotel descreve inicialmente o tamanho, a distribuição espacial e algumas características da rede hoteleira brasileira. A seguir estuda o pessoal ocupado no setor, estimado o contingente diretamente envolvido e analisando sua distribuição por área de atividade, nível de escolaridade e salários médios.

PALAVRAS-CHAVE: Mercado de trabalho em Turismo; hotelaria; característica; mão-de-obra; Brasil.

ABSTRACT: This article is based on the results of the research "Outlooks and Conditions of the Tourism Work Market - Hotel Sector". It describes the size, spacial distribution and other characteristics of the Brazilian hotels. It focus on the workers of this sector and analyses their distribution, education and the average salary.

KEY WORDS: Tourism work market: hotels: characteristics; workers; Brazil.

\section{Introdução}

Desde o início da década de 90, a economia brasileira tem experimentado reformas estruturais de extrema significância, que podem gerar, a longo prazo, as condições para a retomada do crescimento econômico. A curto prazo, entretanto, as reformas produzem um custo elevado, notadamente sobre o mercado de trabal ho. De um lado, a reorganização produtiva da indústria, derivada da crescente abertura \footnotetext{
Economista. Doutor pela Faculdade de Economia e Administração da USP. Professor Assistente-Doutor da FEA-US:

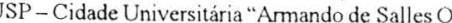
prédio 2 - 005508-900 - São Paulo - SP - Fax: (55-11) 818-6013 - (e) enriquez @) usp.br
}

para o Exterior, de outro a progressiva automação no mercado financeiro, a desestatização e a reforma administrativa conduzem para uma redução expressiva de postos de trabalho com carteira assinada. Em decorrência, tem aumentado o desemprego e o grau de informalidade do mercado de trabalho.

Para diminuir o custo social do ajuste cm curso com o Plano Real, várias ações compensatórias têm sido traçadas. O sistema de seguro-desemprego consolidou-se e uma série de programas de treinamento financiados com recursos do Fundo de Amparo ao Trabalhador - FAT, e implementados via convênios entre o Ministério do Trabalho e as Secretarias Estaduais do Trabalho foi disseminada pelo País. Além disso, tem-se discutido a ampliação do acesso ao crédito aos que perdem seus empregos e pretendem abrir por conta própria pequenos negócios.

Todavia, mesmo que essas ações governamentais produzam efeitos, elas não serão suficientes para minimizar o problema, surgindo, desse modo, a necessidade de medidas complementares. Nessa perspectiva é importante considerar as múltiplas alternativas que o crescimento do setor Turismo pode oferecer. As próprias características desse setor - predominantemente prestador de serviços e interagente com muitos outros setores da economia, mormente transportes, alimentos, construção civil etc.-, levam-no a impactar de maneira positiva no nível de emprego, como analisou Rabahy (1990).

Torres (1991), por sua vez, avalia que cerca de $85 \%$ das atividades turísticas são pertinentes ac setor Serviços, que detém um coeficiente de absorção - relação média trabalho/produção - quc supera em quase $50 \%$ a média nacional, conforme dados fornecidos pela matriz de relações intersetoriais do Instituto Brasileiro de Geografia c Estatística-IBGE. Esseautor acrescenta que o setor deve ser encarado, ao lado de outros abśorvedores de mão-de-obra, também como estratégico, tanto nas políticas de estabilização do nível de emprego, como nas políticas de crescimento que busquen maximizar a utilização de mão-de-obra em primeiro lugar e a seguir a produção

A partir dessas observações, este artigo procura enfatizar a vocação absorvedora de mão-de-obra do setor Turismo, notadamente daquela de baixa escolaridade. É decorrente dos resultados obtidos pela pesquisa da Fundação Instituto de Pesquisas Econômicas - Condições e Perspectivas do Mercado de Trabalho no Setor Turismo - Segmento Hotel (Fipe, 1995), coordenada por Wilson A. Rabahy e realizada a partir de uma amostra de hotéis distribuídos pelos vários recantos do Brasil. Inicialmente, são considerados o tamanho e a distribuição da rede hoteleira no Brasil, em seguida apresenta-se uma estimativa sobre o contingente de mão-de-obra ocupada na mesma, e, por último, descrevem-se algumas características gerais da ocupação, tais como as áreas de atividade, os niveis de escolaridade e o salário médio do pessoal ocupado.

\section{Rede Hoteleira: Tamanho e Distribuição}

O cadastro da Embratur registrou cm dezembro de 1994 um total de 2.366 meios de hospedagem no País, com uma distribuição geográfica bastante heterogê- 
nea. Os Estados de São Paulo, Rio de Janeiro, Minas Gerais c Paraná respondiam por mais de $55 \%$ dos estabclecimentos c $55,2 \%$ das unidades habitacionits Considerando-se o agregado das regiõcs Sul e Sudeste, csses percentuais atingiam, respectivamente, $73,1 \%$ do total dos meios de hospedagem e $72,3 \%$ do total das unidades habitacionais do País. Desse modo, os dados evidenciaram uma forle concentração quer nos meios de hospedagem, quer de unidades habilacionais nas regiões Sul e Sudeste do Brasil.

Quanto à classificação, por número de cstrelas, as informações mostravam que $18 \%$ da rede hoteleira estava classificada em quatro ou cinco estrelas, 1994. Os Estados do Rio Grande do Sul c Minas Gerais apresentaram participação bem inferior à média nacional, respectivamente, $9,9 \%$ e $11,7 \%$, enquanto os Estados de Alagoas (25\%) c Ceará $(23,7 \%)$ mostravam participação superior a media brasileira.

Com as informações relativas ao número de meios de hospedagem c de unidades habitacionais, calculou-se o tamanho dos estabelecimentos cadastrados No Brasil, o tamanho médio dos estabelecimentos situava-se $\mathrm{cm} 5$ ) unidades habitacionais. Essa média sobe significantemente no Distrito Federal, onde a rede hoteleira local possuia, em média, 100,2 unidades habitacionais. Por sua vę, os Estados do Rio Grande do Sul e de Pernambuco foram os que apresentaram meno número de habilaçõcs por unidade de estabelecimento, em média, respectivamente 53,2 e 49,5 unidades habitacionais.

Deve-se assinalar, contudo, que o Guia + Rodas (1995) fornece informaçõcs que mostram um universo bem mais expressivo que o cxistente no cadastro da Embratur: 5.126 meios de hospedagem e 227.933 unidades habitacionais, confirmando, também, que os maiores niveis de concentração estavam nos Estados de São Paulo, Rio de Janeiro, Minas Gerais e Santa Catarina, com 50\% do total dos meios de hospedagem e equivalente proporção de unidades habitacionais catalogadas Essa diferença observada, quer no total de meios de hospedagem, quer no total de unidades habitacionais, deve-se ao fato de que no cadastro do Guia \& Roclas consta um número expressivo de estabelecimentos de pequeno portc, os quais não cstavam incluídos no cadastro da Embratur.

Os dados desse Guia, por outro lado, mostram que nas capitais dos Estados situavam-se cerca de 18\% dos meios de hospedagem c 32\% das unidades habitacionais. Por sua vez, o número médio de unidades habitacionais foi de 44, un número menor do que o calculado pelos dados da Embratur. A existência de maior número de estabelecimentos de pequeno porte no cadastro do Guia if Rodas. relativamente ao da Embratur, ć a variável responsável por essa diferença.

É importante destacar que as informações sobre as dimensões da rede de hospedagem no Brasil são relativamente precárias e deixam de considerar umi parcela muito significativa da oferta de alojamentos, notadamente em hotéis scm classificação e pensões. Em termos internacionais, nossa participação ć relativamente pequena. Segundo a Organização Mundial de Turismo - OMT, da oferti mundial de alojamentos, estimada em 11,3 milhões de unidades habitacionais cu 1992, o Brasil detinha cerca de $2 \%$, percentual calculado utilizando-se o universo do Giuia f Rodas. Dentro desse total. a Europa participa com $+3 \%$ alingindo $80 \%$ ao se adicionar a oferla da Ásia c Eslados Unidos. o que mostra que há um largo cspaço para o crescimento do sctor hotelciro naciona.

Em função da criação do Fungetur. durante cerca de 25 anos, c postcriormentc, do Fiscl. hourc

tendo os dados colclados revelado d 3\% dos holéis possuem atć 30 anos de funcionamento. A pesquisa conslatou. lambém. que. decorrido esse lapso de tempo, o próprio setor produziu internamente boa parcela de seus dirigentes: perto de $30 \%$ dos cmpresários declararam ter origem na própria atividade turística Apurou-sc, por outro lado, que. do conjunto de hotéis pesquisados, 7()\% são independentes, ou scja. não fa\%cm parte de nenhuma rede hoteleira. c $95 \%$ deles são administrados por scus propriclários.

\section{Pessoal Ocupado: Avaliaçāo do Contingente}

De uma amostra plancjada de 280 hotéis. foram efetivamente pesquisados 173,1 cndo sido a variá

os resultados da pesquisa por tamanho de estabelecimento: pequeno (até 20) cmpregados); médio (cntre 2 () c 5 () cmpregados); c grande (mais de 5 () cmpregados).

Os dados amostrais cridenciaram que, na média geral. os hotćis empregan de forma permanente +9.2 pessoas: os de pequeno porte, cerca de $+3 \%$ do total, 1 ĉm cm média c de forma permanentc. 12 cmpregados: os de lamanho médio, $35 \%$ do tolal, têm 36 cmpregados de forma permanente; cnquanto os de grande porte, 22\% do total, mantêm $\mathrm{cm}$ seus quadros. $\mathrm{cm}$ média, 139 cmpregados permanentes.

Considerando-se o tolal de 5.126 meios de hospedagem, a aplicação da média geral obtida no processo de amostragem conduz ao cxpressivo número de 252,3 mil cmpregados permanentes na rede hotcleira nacional. A esse tolal devemSe somar os cmpregados ıemporários c aqueles quececculam sen içosı erceirizados Quanto ao número de temporários, os dados da amostraindicam que eles represenlam, cm média, aproximadamente $9.7 \%$ dos permanentes, ou scja. um contingente nacional de cercal de 24.5 mil cmpregados

Para avaliar o número de traballhadores que realizam senviços terceirizados. tomaram-se informações relativas ao gasto médie por hotel cfeluado com serviços de terceiros c admitiu-sc, por hipótesc. que os terccirizados tcriamo mesmo sálário médio que os vinculados dirclamente ao setor. Partilu-sc, lambém, da hipótese de que o cuslo dircio com pessoal representaria $7(1) \%$ dos gastos com serviços de tcreciros, c ainda que o acréscimo de cncargos sociais sobre a folla de pagamento dobrasse scu valor original. Dessa forma. foi possivel

$6,1 \%$ do pessoal permancntc, ou scja. cm 15,4 mil cmpregados.

Constitui-se da maior importância, por outro lado, discutir as discrepâncias nos números referentes ao tolal de meios de hospedagem. As estatisticas disponiveis. com dados mais recentes, por estarem roltadas para out ras finalidades. deixam 
de incluir uma gama de estabelecimentos que compõem a oferta global de alojamentos: hotéis sem classificaçĩo. pensões. campings. albergues etc.

Una avaliação. embora superficial. da dimensĩo desse componente pode ser inferida a partir do (iura Nacional cle ('ompras, Turismose Serviçoss publicado pelit London Guias. cm 1987. cujo levantamento indicava que. cm 1985. cxistiam 1.7155 hotćis classificados com cstrclas e 9.\$22 hotéis scm classificação

Cerlamente esses dados se altcraram ao longo do tempo. porém a hipótese mais provável ć a de que estejam subestimados. Corrigindo-sc apenas o número de hotéis classificados com estrelas. $2.366 \mathrm{~cm} 1994$. conforme a Embratur. obtćm-se 11.788 meios de hospedagem, utilizando-se o dado da London Guias

Nos cálculos anteriores, considerou-se o universo do Curia + Rodas- 5.126 meios de hospedagem - mas se for adotado o total cxpandido a partir do London Guias, outros 6.662 estabelecimentos seriam incorporados a esse total. Supondose, de forma bastante conservadora que, $\mathrm{cm}$ média, esses hotéis sem classificaçiōo cmpreguem cinco funcionários. obter-sc-ia um novo contingente de 3.3 .3 mil compregados.

Assim, a partir dessas hipóteses, pode-se chegar a uma estimativa provarelmentc bastante parcimoniosa do total de empregos diretos no setor hoteleiro: 2.52 .3 mil cmpregados permanentes; 24.5 mil temporários: $15 .+$ mil terceirizados c 3.3 .3 mil cm holćis sem classificação. Ao todo ter-se-ia um total de 32.5 .5 mil cmpregos diretos. neste setor de atividade.

\section{Características Gerais da Ocupação na Hotelaria}

\section{Distribuição por Área de Atividade}

O pessoal ocupado no sctor pode ser distribuido em cinco principais áreas de ocupação: Recepçĩo. Governança, Restaurante. Cozinha e Administraçĩo Dessas áreas, Recepçĩo c Gorcrnança sĩo as mais absorvedoras de pessoal. sendo que cm conjunto detĉm $60 \%$ do cmprego no setor hotclciro.

Da análise das informações da pesquisa se depreende que os hotéis maiores. catcgoria em que normalmente se incluem os mais luxuosos. incorporam ha composiçĩo do produto final que oferecem uma parcela relativamente maior de mão-de-obra. A participação do gasto com pessoal sobre o faturamento passa de $25 \%$ nos hotéis pequenos para aproximadamente $31 \%$ nos de maior porte

A pesquisa revelou, também. que certas ocupações, principalmente as de chefia ou de maior ní el de especializaçĩo. só cstão presentes nos hotéis de maior portc. Isto porque. $\mathrm{cm}$ funçĩo do produto oferecido. há maior demanda combinada com crigências de maiores qualificações nos holéis mais luxuosos relativamente aos demais. Os serviços tendem a ser mais sofisticados e diversificados à medidá que o holel se torna mais calcgorizado e de maior porte. Por si só, isso já concorrerial para determinlar a presença ou não de profissionais especializados em sua c.recuçīo. Dere-se Icmbrar lambém que a incristência. no quadro de pessoal. do profissional especializado num determinado tipo de sen iço nìo significa necessariamente que esse serviço não sça oferecido aos usuários do hotel. Eventualmente o senviço ć creculado por um profissional que tem outra ocupaçĩo principal (polivalência de funçõcs).

A distribuição do pessoal por árcas de ocupação, segundo o porte do hotel. mostra que nos maiores as áreas de Cozinha e Restaurante alocam 35\% do pessoal permanente, enquanto nos pequenos esse percentual cai para 16\%. Isso ocorre até mesmo porque boa parte dos hotćis pequenos nem dispõem de Reslaurante.

A árca de Administração. claramente uma atividade-meio. ou sc̣ja. nãovolıada diretamente à produção de serviços aos usuários do hotel, absorve 19\% do pessoal nos estabelecimentos pequenos. enquanto nos grandes nĩo chegáa melade dessa proporção. Entretanto, apesar de serem poucos os cmpregados administrativos nos hotćis de pequeno porte. constituem um contingente importante em virtude do reduzido número de pessoas que eles cmpregam.

Dere-se salientar que a pesquisa registrou que nos hotéis de pequeno porte não se encontram detcrminadas ocupações. Assim:

- na área de Recepçĩo, não se encontraram ocupações como clıefe de telefonista, caixa de recepçĩo, correntista c ascensorista;

- na área de Gor crmança, incrisıem as ocupações de clıefe de rouparia c costureira;

- na de Reslaurante, não há primeiro maitre, cliefe de bar, chefe de fila, sommelier. clefe de copa de andar, barman. garçom de bar. cambuzciro e commis de bar:

- na de Cozinha, não se encontraram cozinheiro de frios, cozinlıciro de guarnições. cozinheiro de molhos, churrasqueiro, açouguciro, chefe confeitciro, confeitciro. padeiro/massciro, ajudante de confeitciro:

- na de Administraçĩo. incxiste o gerente de recursos humanos.

Somente cssas ocupações, não-observadas em nenlıum dos estabelecimentos de menor porte, representam 12\% do pessoal permanente nos hotéis maiores. Além di

nos holès, não têm cexpressão numérica significativa, ou scjal, são ocupações que acabam por aparecer com percentuais bastante reduzidos no quadro geral das ocupações. mas que não estão presentes na maior parte dos holćis menores pesquisados.

\section{Nivel de Escolaridade}

A c.remplo da maioria dos ramos de atividade cconômica, na hotelaria lambém se observa a predominância, cm larga cscala, de mão-de-obra com baìo 
nivel de qualificação. Os dados da pesquisa mostram que cerca de $67 \%$ do pessoal permanente possui, no máximo. cscolaridade atć o l’ grau

Esse percentual se altera significativamente quando se analisa cada area de atividade do setor. Nota-se que cm torno de 88\% do pessoal de Goremança e $87 \%$ do pessoal de Cozinha possui formação atć o $1^{\circ}$ grau. E. da parcela que não possu escolaridade (perto de $5 \%$ do pessoal da rede holeleira), $64 \%$ preslam serviços ma área de Governança e $20 \%$ na de Cozinha.

Em outro cetremo, dos cmpregados que possuem nivel superior - cerca de $5,5 \%$ do total - . $68 \%$ cstão trabalhando cm scrviços administrativos c os demiais (32\%) na área de Recepção. Essas duas áreas são as que delêm os maiores níveis de escolaridade na rede holeleira: $5+\%$ das pessoas da Recepção e $87 \%$ da Adıninis tração possuem escolaridade igual ou superior ao $2^{\prime \prime}$ grau. O setor de Restaurante possui o maior contingente com escolaridade nos niveis intermediários: 77\% com primeiro grau c $22 \%$ com $2^{\circ}$ grau.

Entretanto. der'e-se ponderar que no setor hoteleiro além da escolaridade formal ć importante a cxperiência na função. Assim, devem-sc incluir cursos de trcinamento, participaçã̃o cm cursos não-regulares clc., pois constitucm-sc fatores mais significativos que o próprio grau de qualificaçĩo formal.

A pesquisal constatou, outrossim. que são menores as cxigências de escolitridade nas ocupações de:

- portciro c mensagciro, na árca de Recepçĩo:

- arrumadcira/camarcira, costurcira, roupcira, lavadcira, passadcira c faxincira na área de Governança:

- garçom. barman. commis de andares, atendente de lanchonete e commis de bar no sctor de Restaurante:

- primciro cozinlıciro, cozinlıciro de guarniçõcs, cozinlıciro de molhos, cozinlıciro de assados e grelhados, cozinheiro familiar. clıurrasqueiro, açouguciro, chefo confeitciro, confeitciro, padeiro/massciro, ajudante de primeiro cozinheiro. ajudante de cozinha, lancheiro/chapeiro, ajudante de confeitciro e peão de cozinha, na área de Cozinha.

Em todas essas ocupações, a pesquisa captou percentuais superiores à média do setor: $67 \%$ do pessoal sem escolaridade ou com atć o ${ }^{\circ}$ grau. Chamou a alcnçio o fato de que, na área da Cozinlaa, somente a ocupação de clicfe de cozinha tem. em média. nivel de escolaridade superior à média geral do pessoal do setor.

As maiores proporções, superiores a $2(0 \%$, do pessoal sem escolaridade foram encontradas nas ocupações de roupcira, faxincira. lancheiro/chapeiro c peĩo de cozinha. Do total de 69 ocupações nas diversas áreas de atividade e. dentre as de menor nivel de cscolaridade, mensageiro, arrumadcira/camareira e garçom. respondem por mais de $35 \%$ do cmprego permanente do setor.

\section{Salários Médios}

Sabe-se que, do ponto de vista econômico, devem-se esperar maiores níveis de remuneração à medida que aumenta a escolaridade da mão-de-obra, e essa regra ambém se observa no setor hoteleiro nacional. Assim, se por um lado observou-se que quase $70 \%$ dos empregados possuem escolaridade máxima de $1^{\circ}$ grau, por outro que quas médio também se situa em patamar elevado: $\mathrm{R} \$ 390,00$. Essa média situouo salário médio tanchonete) até $\mathrm{R} \$ 1.733,30$ (gerente se entre os limites de $\mathrm{R} \$ 180,50$ (atendente de lanchonete) ate $\mathrm{R} \$ 1.733,30$ (gerente de contabilidade), o que equivale a um desvio de $52 \%$ abaixo da média geral,
relativamente ao menor salário e de $342 \%$ acima da média, issoquando se considera o maior salário.

A área de Governança, que detém $11 \%$ do pessoal ocupado classificado como "sem escolaridade", é a quc apresenta o pior nivel salarial -em torno de $32 \%$ inferior à média geral. Por sua vez, a área de Administração, destacadamente a que inferior à méria nível de escolaridade, é a de maior discrepância em relação à média: os salários nessa área, considerando o conjunto, situam-se em torno de 162\% superiores à média salarial geral.

Contrariando a relação csperada, a área de Rccepção apresentou o segundo pior salário - cerca de 18\% abaixo da média salarial geral, embora detenha o segundo melhor grau de escolaridade. O salário, relativamente baixo nessa área, face ao nivel de escolaridade, parece estar associado à maior oferta de profissionais dirigidos a essa área no mercado.

A área de Cozinha, que apresenta na quase totalidade de suas ocupações percentuais de baixa escolaridade ainda maiores que a média geral, apresentou, no conjunto, salário muito próximo à média geral do hotel. É a segunda melhor área em termos de remuneração.

Também neste caso intervêm na explicação dos salários, relativamente mais altos, não os níveis de escolaridade, mas fatores associados à experiência c a out ros tipos de treinamento. Pesa igualmentc a disponibilidade desses profissionais - a pesquisa verificou que a contratação de recursos humanos nesta área é considerada como difícil ou muito difícil cm 33\% dos entrevistados. Percentual este relativamente maior do que o encontrado para o total das ocupações, em que o grau de dificuldade na contratação, segundo a pesquisa, reduz-se para cerca de $26 \%$ dos entrevistados.

As ocupações pertinentes ao grupo Restaurante também no conjunto apresentaram salário médio próximo da média global. Contribui estatisticamente para explicar este comportamento o fato de que a ocupação de garçom, mais da metade do pessoal do grupo, tem salário relativamente próximo da médiageral. Em termos de escolaridade, conforme salientado anteriormente, esta área detém $77 \%$ do pessoal com $1^{\circ}$ grau e outros $22 \%$ com $2^{\circ}$ grau.

Excluindo a árca Administrativa, onde as discrepâncias em termos salariais e de escolaridade são muito acentuadas em relação à média geral, os salários mais

2. Valores de junho de 1995 
altos são pagos às ocupações de chefe de recepção. governanta geral. princiro maitre, sommelier, chefe de cozinha, cozinheiro de frios, cozinheiro de guarnicões. cozinheiro de molhos, cozinheiro de assados e grelhados e chefe confeiteiro. Esse conjunto de ocupações possui remunerações com desvio em relação à média do sctor superior a $50 \%$. Contudo, destacam-se as ocupações dechefede recepção, governanta geral e primeiro maitre em termos de maior escolaridade: mais de $50 \%$ do pessoal possui pelo menos o $2^{\circ}$ grau, enquanto nas demais ocupações relacionadas predomina o nível educacional formal de até o $1^{\circ}$ grau $\mathrm{cm}$ mais de $60 \%$ dos casos. As piores remunerações, com desvios superiores a $40 \%$ abaivo da média, são recebidas pelos mensagciros, ascensoristas, lavadciras, passadeiras, faxinciras, copeiros de restaurante, copeiros de andares, atendentes de lanchonete, commis de bar, ajudantes de cozinha, lancheiros/chapeiros, e peões de cozinha. Nestas ocupações, à exceção de ascensorista, em $85 \%$ dos casos a escolaridade atinge 110 máximo o $1^{\circ}$ grau.

\section{Consideraçōes finais}

Com as informações dessa pesquisa, pode-se afirmar que é expressiva a magnitude do contingente empregado na rede hotcleira de forma direta, embora esteja ele subestimado. Também ficou evidente que o setor tem como característici ser absorvedor de mão-de-obra com baixo padrão de qualificação, quase $70 \%$ do efetivo com escolaridade atć o $1^{\circ}$ Grau.

No setor hoteleiro brasileiro, as atividades mais representativas, $\mathrm{cm}$ termos do total ocupado, são encontradas nas áreas de Recepção e Governança, sendo que somente as ocupações relacionadas com a área de Recepção e Administração possuem mais da metade de seu contingente com formação igual ou superior ao $2^{\circ}$ grau. Na área Administrativa essa proporção ultrapassa 85\%.

Quanto aos salários, os dados da pesquisa mostram que na área Administrativa há forte discrepância em relação à inédia geral. As informações por área de atividade mostraram alta correlação entre escolaridade e salários tanto na área de Governança, que detém os piores índices de escolaridadec, também, na média o pior salário, quanto na Administrativa, que conta com a melhor escolaridade c também os maiores salários.

Nas áreas de Cozinha e Recepção, onde houve inversão na correlação esperada, o fato estaria associado à questão da experiência na função c/ou disponibilidade desses profissionais no mercado de trabalho

\section{Referências Bibliográficas}

FIPE. Fundação Instituto de Pesquisas Econốmicas 1995. Condições e perspectivas do mercado de trabalho no setor de tursmo - segnento hotel - FIPE/USP GUIA Nacional de Compras, Turismo e Serviços. 1987. London Guias GUIA 4 RODAS. 1995 São Paulo: Abril

RABAHY. Wilson A. 1900. Planejamiento do Turismo - estudos econonnicos e fundamientos econoniétricos. São Paulo Ediçôes Loyola.

1091. Turismo e emprego na economia brasileira. Turismo em Análise. São Paulo, ECA/USP. v. 2 n. I. Maio 